\section{Pharmacy counter assistants and oral health promotion: an exploratory study}

\author{
B. J. Steel ${ }^{1}$ and C. Wharton ${ }^{2}$ \\ VERIFIABLE CPD PAPER
}

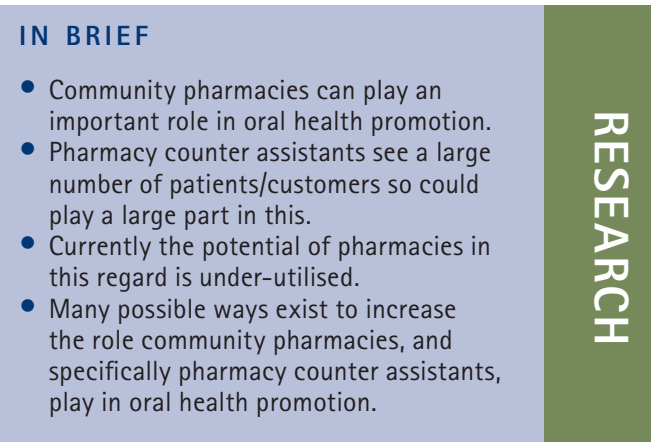

\begin{abstract}
Background The involvement of community pharmacists in oral health promotion is being increasingly recognised and studied. However, a large proportion of interactions in community pharmacies take place with pharmacy counter assistants rather than the pharmacist, and the role of pharmacy counter assistants in oral health promotion has received little or no attention until now. Aims To clarify the current state of affairs on pharmacy counter assistants' involvement with oral health promotion. Design and methods A postal-questionnaire-based survey of pharmacy counter assistants across East Yorkshire, North Lincolnshire and the Doncaster area. One hundred addresses were included and 35 responses were received. Results Pharmacy counter assistants are infrequently approached by the public for advice on matters of oral health and advice is not often volunteered despite a reasonable knowledge of the subject. Respondents identified a role for themselves in educating patients/customers, which they are keen to expand. Conclusions The expansion of the pharmacy counter assistant's role in oral health promotion would be of value to patients/customers. This should include increased opportunistic education and a more integrated position of pharmacy within a holistic health promotion strategy.
\end{abstract}

\section{INTRODUCTION}

The pharmacy profession is currently moving towards a more active and integrated role in healthcare as a whole, with a strong emphasis on prevention. ${ }^{1-3}$ Government ${ }^{2,4}$ and Royal Pharmaceutical Society of Great Britain (RPSGB) (now the Royal Pharmaceutical Society (RPS) $)^{5}$ policy and guidance very much promote active health promotion. There is already awareness within the pharmacy profession of the importance of an oral health component to this. The RPSGB/RPS encourages a more 'proactive approach to maximise opportunities in oral health' by pharmacists. ${ }^{5}$ Also, the Department of Health's 2006 document 'Choosing better oral health', ${ }_{4}$ which sets out a framework for improving the nation's oral health, specifically mentions the potential contribution of pharmacists in oral health promotion (OHP).

\footnotetext{
${ }^{1 *}$ General Dental Practitioner and Medical Student, Hull; ${ }^{2}$ Community Pharmacist, Whitley Bay, Tyne and Wear ${ }^{*}$ Correspondence to: Dr Ben Steel Email: b_steel_1_the@yahoo.co.uk
}

\section{Online article number E19}

Refereed Paper - Accepted 24 July 2011

DOI: $10.1038 /$ sj.bdj.2011.938

${ }^{\circ}$ British Dental Journal 2011; 211: E19
Many factors lend support to a more active role of community pharmacies in OHP. Importantly, community pharmacies occupy a geographic position in the heart of communities. ${ }^{1}$ The public is trusting of advice received, and a very large number of people visit, ${ }^{6}$ many of whom will, by virtue of co-morbidities or medications, have an increased propensity to oral disease. A wide range of oral health-related products is usually sold and the infrastructure is in a primary care setting and is therefore accessible. Community pharmacies can be attended by the well and the ill without fee or appointment, and act as a signpost to access other health professionals. Despite these factors, the potential of pharmacies in OHP is apparently still very under-utilised.

A role for pharmacists in OHP has been previously investigated in the literature. ${ }^{7-10}$ However, a large proportion of interactions with patients/customers (the terms 'patient' and 'customer' are used interchangeably throughout this paper) in community pharmacy occur with a pharmacy counter assistant (PCA), also known as a medicines counter assistant, rather than with a pharmacist. PCAs are pharmacy auxiliaries, required by the General Pharmaceutical
Council (GPhC) to undertake some training but not to register. ${ }^{11}$ The remit of PCAs is to assist with the sale of over the counter medicines and the issuing of prescription medicines, and in answering patient/customer queries. The role PCAs are playing, or could play, in OHP, does not appear to have been formally studied; a literature search yielding only one very brief mention. ${ }^{12}$ Published material about OHP from the Department of Health and the RPSGB/ RPS also does not appear to make mention of PCAs. ${ }^{2,4,5}$ This study aims to explore this area and has the following objectives:

1. To clarify the current state of affairs in community pharmacy by addressing the following questions:

- Do PCAs have the opportunity to give advice on oral health matters?

- What advice do PCAs give on oral health matters?

- How good is the knowledge of PCAs on different oral health topics and how much training have PCAs had on oral health?

- How confident are PCAs in providing advice on oral health matters?

- Do PCAs perceive any barriers to their provision of OHP? 
- Do PCAs perceive a role for themselves in OHP and do they wish to expand this role?

2. To explore the possible role of PCAs in OHP in community pharmacy.

\section{METHODOLOGY}

The method of data collection in this study involved the mailing of a postal questionnaire to community pharmacies across East Yorkshire, North Lincolnshire and the Doncaster area. A stratified sample was used. All of the community pharmacies in this whole geographical area were grouped into nationwide chain, regional chain, independent and supermarket pharmacies. These groups were then each grouped into those attached and not attached to GP practices, and individual pharmacies were then chosen at random from within these groups to form the sample. Ethical approval was not required.

The questionnaire comprised asking the respondents to quantify, within provided range groups, the frequency that oral health advice is requested of them, and the frequency that oral health advice is provided by them whether requested or not. In order to assess PCAs' oral health knowledge, ten questions addressing major prevention issues as emphasised in the Evidence-Based Toolkit for Prevention ${ }^{13}$ were drawn up and included in the questionnaire; these questions were open so as to minimise response bias. Respondents were asked how much training on oral health they have received. Confidence of PCAs in the main areas of oral health was sought by placement on a five-point scale from 'very confident' to 'very unconfident'. Finally, respondents were asked in an open question what barriers they perceive to themselves providing oral health advice, and in closed questions whether they perceive a role for themselves in this regard, and whether this role should be expanded. The questionnaire was drawn up as a consensus between co-authors of different disciplines, and not piloted before sending. Responses were anonymous to ensure freedom of expression, and open questions were used wherever possible so as to avoid prompting the respondent. Details such as the category or location of the pharmacy, and demographic data such as respondent age, gender, training or experience, were not sought. Although this removes the ability to analyse the results

Table 1 The number of respondents asked for advice on oral health topics, by frequency

\begin{tabular}{|l|l|l|l|l|l} 
& $\begin{array}{l}\text { Less than } \\
\text { once per } \\
\text { month }\end{array}$ & $\begin{array}{l}\text { Less than } \\
\text { once per } \\
\text { week }\end{array}$ & $\begin{array}{l}1 \text { to } 5 \text { times } \\
\text { per week }\end{array}$ & $\begin{array}{l}5 \text { to } 10 \\
\text { times per } \\
\text { week }\end{array}$ & $\begin{array}{l}\text { More than } \\
10 \text { times } \\
\text { per week }\end{array}$ \\
\hline Toothpaste & 26 & 5 & 3 & 1 & 0 \\
\hline Mouthwash & 7 & 15 & 10 & 2 & 1 \\
\hline $\begin{array}{l}\text { Cleaning } \\
\text { in-between teeth }\end{array}$ & 27 & 5 & 3 & 0 & 0 \\
\hline Gum care & 23 & 6 & 4 & 1 & 1 \\
\hline Denture hygiene & 23 & 9 & 2 & 1 & 0 \\
\hline Tooth erosion & 30 & 4 & 1 & 0 & 0 \\
\hline Dry mouth & 18 & 12 & 4 & 1 & 0 \\
\hline $\begin{array}{l}\text { Dietary advice in } \\
\text { relation to oral health }\end{array}$ & 32 & 3 & 0 & 0 & 0 \\
\hline Smoking cessation & 6 & 5 & 17 & 5 & 2 \\
\hline Alcohol consumption & 28 & 6 & 1 & 0 & 0 \\
\hline
\end{tabular}

Table 2 The number of respondents giving advice on oral health topics, by frequency

\begin{tabular}{|l|l|l|l|l|l} 
& $\begin{array}{l}\text { Less than } \\
\text { once per } \\
\text { month }\end{array}$ & $\begin{array}{l}\text { Less than } \\
\text { once per } \\
\text { week }\end{array}$ & $\begin{array}{l}1 \text { to } 5 \text { times } \\
\text { per week }\end{array}$ & $\begin{array}{l}5 \text { to } 10 \\
\text { times per } \\
\text { week }\end{array}$ & $\begin{array}{l}\text { More than } \\
10 \text { times } \\
\text { per week }\end{array}$ \\
\hline Toothpaste & 21 & 8 & 5 & 1 & 0 \\
\hline Mouthwash & 7 & 14 & 11 & 2 & 1 \\
\hline $\begin{array}{l}\text { Cleaning } \\
\text { in-between teeth }\end{array}$ & 22 & 9 & 3 & 0 & 1 \\
\hline Gum care & 17 & 12 & 5 & 0 & 1 \\
\hline Denture hygiene & 17 & 13 & 4 & 1 & 0 \\
\hline Tooth erosion & 25 & 8 & 2 & 0 & 0 \\
\hline Dry mouth & 20 & 9 & 4 & 2 & 0 \\
\hline $\begin{array}{l}\text { Dietary advice in } \\
\text { relation to oral health }\end{array}$ & 24 & 6 & 4 & 1 & 0 \\
\hline Smoking cessation & 3 & 7 & 17 & 5 & 3 \\
\hline Alcohol consumption & 22 & 8 & 5 & 0 & 0 \\
\hline
\end{tabular}

by respondent strata it was decided in the interest of brevity to concentrate more on direct clinical questioning.

A copy of the questionnaire with a covering letter requesting participation by a PCA (the covering letter requested that the answers given on the questionnaire should relate to the individual PCA and not to the whole pharmacy) and a stamped self addressed envelope were sent to each of the 100 pharmacies that were chosen, and initially 20 responses were received. A second such pack, with the covering letter requesting participants not to respond if they had already responded, was sent to the same 100 pharmacies after an eightweek time interval, yielding a further 15 responses, thus giving a total response rate of 35 out of 100 . Although a fairly low response rate, it is in line with other studies of similar design and target. ${ }^{9}$

\section{RESULTS}

The data that were obtained from the responses to the questions in the questionnaire are detailed in this section.

\section{Are PCAs being asked for oral health advice?}

The results of this survey show that generally speaking PCAs are not often asked for advice on oral health matters (Table 1 , Fig. 1); the topic that seems to be least often asked about is dietary advice in relation to 


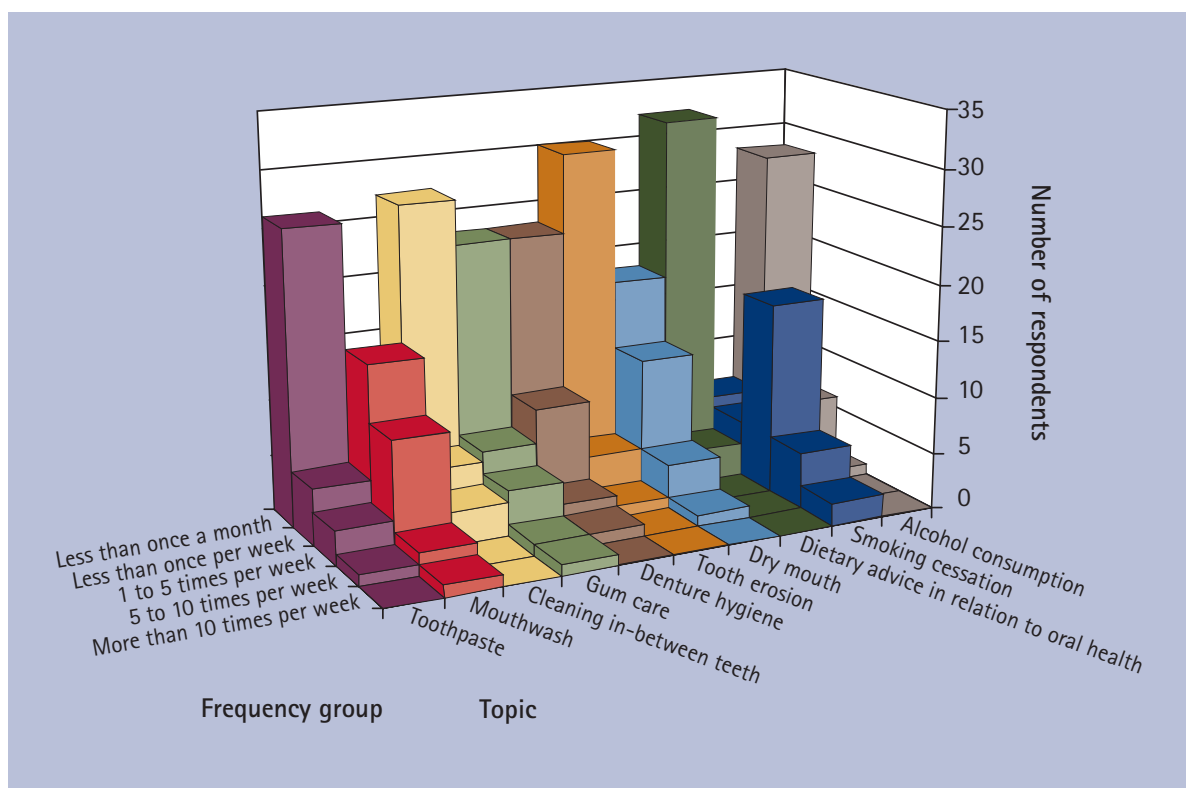

Fig. 1 Frequency of advice given, by topic

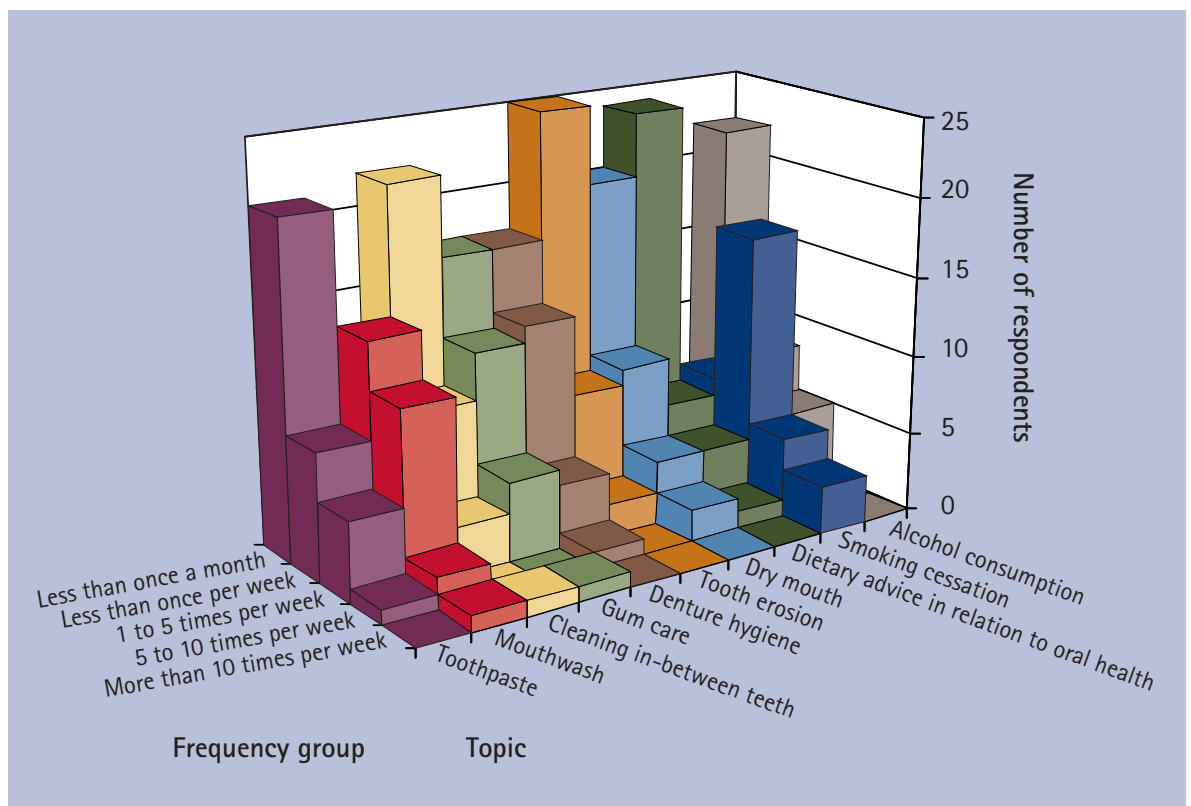

Fig. 2 Frequency of patient/customer enquiries, by topic

oral health. The most frequent enquiry in this study seems to be regarding smoking cessation, with 49\% ( $n=17)$ of respondents receiving one to five enquiries about this topic per week, and 20\% $(n=7)$ of respondents receiving more than five enquiries about this topic per week. Also, in contrast to the other topics except smoking cessation, $37 \%(n=13)$ of respondents receive enquiries about mouthwash once per week or more.

\section{Are PCAs providing oral health advice?}

Generally speaking, the frequency of providing oral health advice is similar to the frequency with which it is sought, which can be seen by comparing Table 1 with stated 'any fluoride', 9\% ( $\mathrm{n}=3$ ) 'adult toothpaste', and 3\% ( $\mathrm{n}=1)$ each 'any the child will use', 'any childrens' and 'follow on toothpaste'. Twenty-eight specific brands were named by 26 respondents. All of the suggested brands were fluoridated, 86\% ( $\mathrm{n}=24$ ) contained $1,000 \mathrm{ppm}$ fluoride or more, and 50\% $(n=14)$ of suggested brands met the recommended level of fluoride for this age of 1,350-1,500 ppm as detailed in the Evidence-Based Toolkit for Prevention. ${ }^{13}$

\section{What age would you advise} toothbrushing to start?

All of the 35 respondents answered this question. Ninety-four percent $(\mathrm{n}=33$ ) of respondents would advise toothbrushing to start when the child's first tooth appears. Of the remaining two respondents, one (3\%) would advise to start at one year of age and the other (3\%) at three years of age.

\section{Which mouthwash, if any, would you recommend for adults for prevention of decay?}

Twenty-eight respondents answered this question, each naming only one mouthwash (seven respondents did not answer this question). Thirty-one percent ( $\mathrm{n}=11$ ) would recommend a fluoride-containing mouthwash, with or without other active ingredients. Twenty-three percent ( $\mathrm{n}=8$ ) would recommend Listerine (none specifically mentioned the fluoride version), and 20\% ( $\mathrm{n}=7$ ) chlorhexidine. Six percent $(n=2)$ stated 'any'.

\section{Which mouthwash, if any, would you recommend for adults for prevention/ treatment of gingivitis/gum disease?}

Thirty-six suggestions were given by 34 respondents (one respondent did not answer this question). Seventy-seven percent $(n=27)$ of respondents would recommend chlorhexidine/Corsodyl, 23\% ( $\mathrm{n}=8)$ Oraldene (hexetidine), and 3\% ( $\mathrm{n}=1)$ Eludril (chlorhexidine and chlorobutanol).

\section{What advice would you routinely} provide to a patient/customer buying a toothbrush or toothpaste (whether asked or not)?

\section{What is the level of knowledge of PCAs regarding maintenance of oral health?}

Which toothpaste would you recommend for use by a six-year-old child?

Thirty-seven suggestions were given by 32 respondents (three respondents did not answer this question). Nine percent $(n=3)$
Forty-eight suggestions were given by 31 respondents (four respondents did not answer this question). Three percent $(\mathrm{n}=1)$ stated 'yes' without specifying what advice they would give, $11 \%(\mathrm{n}=4)$ said they would give none and 9\% $(n=3)$ stated 
they would not give advice unless specifically asked. One of these reported that if they were asked for advice they would only be able to "differentiate between children's, adult, soft, hard, etc, some clean the tongue', another saying it is very rare for them to be asked for advice on this subject. Seventeen percent $(n=6)$ would help to select the correct type for the patient's needs, including for sensitive teeth or whether they are buying one brand of toothpaste for all the family to use, and $3 \%(\mathrm{n}=1)$ stated to make sure that the toothbrush is of the correct type and bristle strength. Eleven percent $(n=4)$ mentioned fluoride, three of whom specifically mentioned fluoride toothpaste. Three percent ( $\mathrm{n}=1$ ) would advise a "non-abrasive toothpaste', $6 \%(\mathrm{n}=2)$ a toothbrush that has bristles that are not too hard, 3\% ( $n=1)$ a medium or electronic toothbrush, and 6\% $(\mathrm{n}=2)$ a soft to medium toothbrush. Six percent $(n=2)$ stated that patients who have sensitive gums or teeth may need a soft toothbrush and 6\% $(n=2)$ that smokers need a hard toothbrush. Seventeen percent $(n=6)$ would advise to replace the toothbrush every three months, 3\% $(\mathrm{n}=1)$ every six weeks, and $11 \%(\mathrm{n}=4)$ 'regularly' Six percent $(n=2)$ would advise to brush teeth twice a day (one of whom would also advise to 'follow with floss and mouthwash if necessary'), 6\% ( $\mathrm{n}=2)$ 'at least twice a day', and 3\% ( $\mathrm{n}=1)$ 'regularly'. Finally, $3 \%(n=1)$ would advise to use only a small amount of toothpaste, and $3 \%(n=1)$ to 'clean between teeth'.

Would you advise/recommend any oral hygiene aids/products for an adult with gingivitis or gum disease and if so what would these be?

Sixty-two suggestions were made by 34 respondents (one respondent did not answer this question). Ninety-two percent $(\mathrm{n}=33)$ would recommend the use of a mouthwash, of which 16 related to chlorhexidine, six Oraldene, and 11 not specified. Nine percent $(\mathrm{n}=3)$ of respondents mentioned toothpaste (two Corsodyl Toothpaste and one Colgate Pro-Relief), 17\% $(\mathrm{n}=6)$ toothbrushing, 20\% ( $n=7)$ the use of floss and $11 \%(n=4)$ Corsodyl gel. Fourteen percent $(n=5)$ would advise the patient to see their dentist. Three percent $(n=1)$ mentioned the possible adverse effects of medication on the gums, with other responses comprising the 'Hummingbird' device $(\mathrm{n}=1)$, 'Oral B' without further details $(n=1)$, and use of an electric brush $(\mathrm{n}=1)$.

\section{What advice would you offer a patient regarding maintenance of denture hygiene?}

Fifty-two suggestions were made by 29 respondents (six respondents did not answer this question). Twenty-nine percent $(n=10)$ of respondents would advise the use of a proprietary denture cleaning tablet, 23\% ( $\mathrm{n}=8$ ) would advise to brush and $3 \%(\mathrm{n}=1)$ to rinse the dentures, and $29 \%(\mathrm{n}=10)$ suggested daily cleaning with no further details. Fourteen percent $(n=5)$ would advise to see the dentist and 3\% $(n=1)$ the hygienist. Nine percent $(n=3)$ would advise to take the dentures out at night and $11 \%(\mathrm{n}=4)$ to store in water overnight. Seventeen percent $(n=6)$ suggested the use of oral hygiene aids comprising toothbrushing $(\mathrm{n}=2)$, floss $(\mathrm{n}=1)$ and mouthwash $(\mathrm{n}=3)$. Six percent $(\mathrm{n}=2)$ would advise to check the fit and a further $6 \%(\mathrm{n}=2)$ to clean after food.

\section{What advice would you offer a patient regarding prevention of tooth erosion?}

Sixty-five suggestions were made by 28 respondents (seven respondents did not answer this question). Only 14\% ( $\mathrm{n}=5)$ of respondents mentioned advising a reduction in acid intake, with 31\% $(\mathrm{n}=11)$ reporting that they would offer advice on lowering the amount of sugar in the diet. Six percent $(\mathrm{n}=2)$ mentioned the 'diet' with no further details, 3\% $(\mathrm{n}=1)$ a reduction in alcohol consumption, and 3\% ( $\mathrm{n}=1)$ increasing intake of fruit and vegetables. Thirty-seven percent $(n=13)$ listed 'toothbrushing' without qualification, 17\% $(\mathrm{n}=6)$ would advise mouthwash and 11\% $(n=4)$ a formulated erosion toothpaste. Seventeen percent $(\mathrm{n}=6)$ would advise the patient/customer to see the dentist. Other answers were brushing twice daily $(\mathrm{n}=3)$, interdental brushes $(n=1)$, floss $(n=6)$, stopping use of a hard brush $(n=2)$, using a straw $(n=1)$, use of fluoride toothpaste $(n=2)$, and use of 'enamel' toothpaste $(\mathrm{n}=1)$.

\section{What advice would you offer a patient regarding smoking cessation?}

Forty-three suggestions were made by 30 respondents (five respondents did not answer this question). Eleven percent ( $n=4$ ) would offer their in-pharmacy smoking cessation course and 6\% $(\mathrm{n}=2)$ their pharmacy's one-to-one scheme. Thirty-one percent $(n=11)$ would offer over-the-counter products such as nicotine patches and gum; one of these (3\%) also listing Champix as a second line to NRT (nicotine replacement therapy). Three percent $(\mathrm{n}=1)$ mentioned 'drugs' and $9 \%(\mathrm{n}=3)$ 'counselling'. Eleven percent $(\mathrm{n}=4)$ would advise the patient/customer to see their general medical practitioner (GMP) and 3\% ( $\mathrm{n}=1)$ mentioned the NHS Stop Smoking service. Other suggestions comprised discussing the health benefits of quitting ( $n=1)$, cancer ( $n=1)$, using leaflets ( $\mathrm{n}=1)$, advising to 'stop ASAP' $(\mathrm{n}=1)$, seeing a 'smoking cessation advisor' $(\mathrm{n}=1)$ and to 'seek advice' $(\mathrm{n}=1)$. Nine percent $(\mathrm{n}=3)$ would question the patient/customer and discuss what quitting method is best for them. Finally, 20\% ( $n=7)$ of respondents focused in their answer on an oral health perspective to smoking, including 14\% $(\mathrm{n}=5)$ discussing toothpaste and $6 \%(n=2)$ tooth staining.

What advice would you give a patient who complains of dry mouth?

Forty suggestions were made by 27 respondents (eight respondents did not answer this question). Twenty-three percent ( $\mathrm{n}=8$ ) would discuss possible links with the patient's medications and 20\% ( $\mathrm{n}=7)$ would offer artificial salivas. Nine percent ( $\mathrm{n}=3$ ) would advise a good fluid intake, $17 \%(n=6)$ for the patient/customer to see their GMP and 11\% $(n=4)$ the dentist. Three percent $(n=1)$ mentioned the use of the 'wham questions'. Six percent $(n=2)$ mentioned the use of gum, one of whom specified sugar-free. One respondent each would advise the use of Biotène mouthwash, Biotène toothpaste, 'glycerin pastilles or a product containing glycerin', sugarfree pastilles, and a non-specified product. Eleven percent $(n=4)$ stated to seek advice from the pharmacist, interestingly the only point in this entire study where this has been mentioned by a respondent.

\section{How much training have PCAs received on oral health?}

Twenty-nine out of 35 respondents answered this question. Forty-six percent $(\mathrm{n}=16)$ reported receiving no training on 
oral health and a further 6\% $(n=2)$ 'not much', with $31 \%(\mathrm{n}=11)$ giving details of training they have received. The type of training reported varied from magazine articles $(n=1)$ and counter assistant training leaflets $(n=1)$, to formal training modules $(n=9)$ both as part of initial qualifications and continuing professional development.

\section{How confident do PCAs feel about providing oral health advice?}

The level of confidence of PCAs in nine oral health categories was split into five groups as shown in Table 3 and Figure 3: very confident, fairly confident, neutral, fairly unconfident and very unconfident. The respondents were asked to state which of these five levels of confidence they think applies to them for each of these nine oral health categories. Thirtytwo respondents out of 35 answered the questions relating to confidence. As can be seen, the majority of responses were either 'fairly confident' or 'neutral'. The results suggest that PCAs feel particularly confident discussing decay in children and adults, and prevention and treatment of gum problems. The major exception to the general trend was that of smoking cessation, where $41 \%$ ( $n=13$ of 32 responses) stated that they are 'very confident'. The category where the next largest proportion of respondents stated that they are 'very confident' was denture hygiene $(19 \%, n=6)$. The categories where the largest proportion of respondents stated that they are 'fairly unconfident' were dry mouth and dietary advice in relation to oral health (19\%, $n=6$, for each). Perhaps reassuringly, in all of the categories only one respondent scored any of the topics as 'very unconfident'; this was for moderation of alcohol consumption.

\section{What barriers are perceived by PCAs to their provision of oral health education?}

Only 17 respondents out of 35 answered this question. Twenty-six percent ( $\mathrm{n}=9$ of 35) stated they perceived no barriers to their provision of oral health education. The eight respondents who perceived barriers listed 13 reasons between them. Interestingly, only six (17\% of 35) listed a lack of training on this subject as a barrier, with other reasons comprising a lack of

Table 3 The number of respondents reporting each level of confidence for each oral health topic

\begin{tabular}{|l|l|l|l|l|l}
\hline & $\begin{array}{l}\text { Very } \\
\text { confident }\end{array}$ & $\begin{array}{l}\text { Fairly } \\
\text { confident }\end{array}$ & Neutral & $\begin{array}{l}\text { Fairly } \\
\text { unconfident }\end{array}$ & $\begin{array}{l}\text { Very } \\
\text { unconfident }\end{array}$ \\
\hline Decay in children & 3 & 20 & 9 & 0 & 0 \\
\hline Decay in adults & 2 & 23 & 6 & 1 & 0 \\
\hline $\begin{array}{l}\text { Prevention/treatment } \\
\text { of gum problems }\end{array}$ & 2 & 16 & 13 & 1 & 0 \\
\hline Denture hygiene & 6 & 10 & 14 & 2 & 0 \\
\hline Dry mouth & 4 & 10 & 12 & 6 & 0 \\
\hline $\begin{array}{l}\text { Dietary advice in } \\
\text { relation to oral health }\end{array}$ & 2 & 14 & 10 & 6 & 0 \\
\hline $\begin{array}{l}\text { Prevention of } \\
\text { tooth erosion }\end{array}$ & 1 & 17 & 12 & 2 & 0 \\
\hline Smoking cessation & 13 & 8 & 10 & 1 & 0 \\
\hline Alcohol consumption & 4 & 13 & 10 & 4 & 1
\end{tabular}

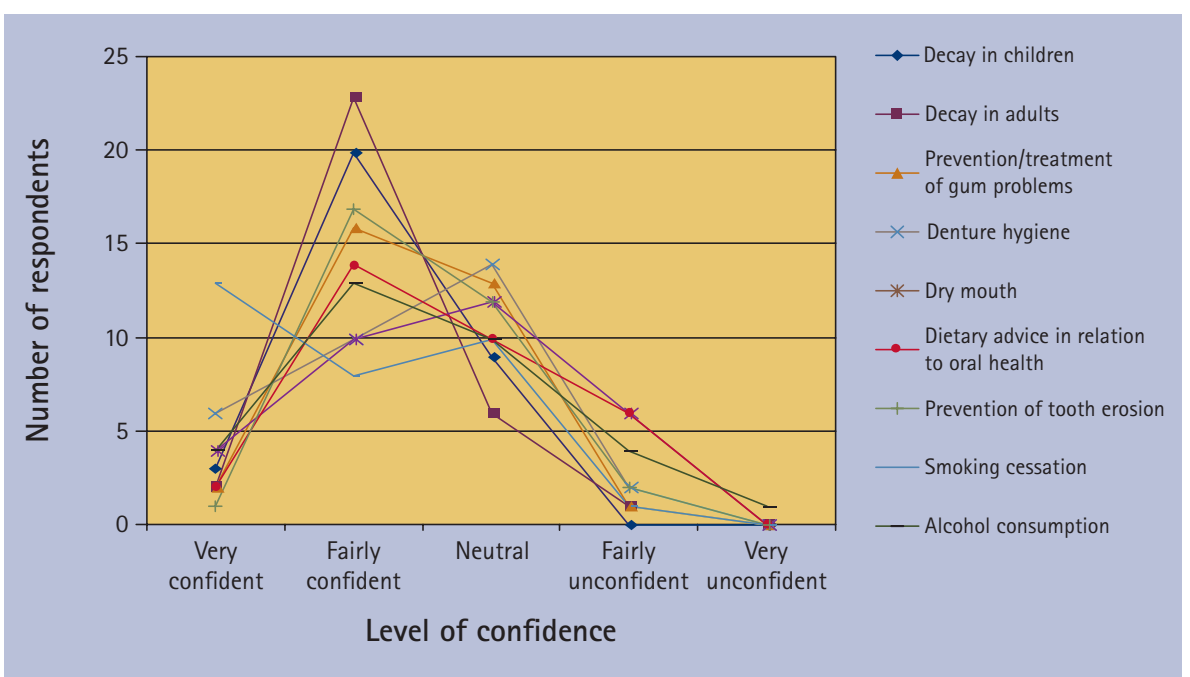

Fig. 3 PCAs' confidence in providing advice, by topic

information to give to patients $(9 \%, \mathrm{n}=3)$ and appropriate products available in the pharmacy $(3 \%, \mathrm{n}=1)$, difficulty deciding when to refer $(3 \%, \mathrm{n}=1)$ and time and staffing issues $(3 \%, \mathrm{n}=1)$. One respondent mentioned 'a PCT-driven scheme may help'.

\section{Do PCAs perceive a role for them- selves in oral health education?}

Thirty-two out of the 35 respondents answered this question, and all but one (89\% ( $\mathrm{n}=31$ of 35)) agreed that PCAs do have a role in the provision of oral health education.

\section{Are PCAs keen to expand their role in oral health education?}

This question also yielded a response rate of 32 out of 35. Eighty-six percent ( $n=30$ of 35) reported themselves to be keen to expand their role in this regard.
Does the correctness of the advice correlate with the level of confidence with which it is given?

Analysis on this matter was possible for some of the oral health topics addressed by this study. These were the topics for which both the advice given and level of confidence of the PCAs in giving it were sought by the questionnaire and clear evidence-based guidelines on the topic were available. This was so for prevention of decay in children, prevention/ treatment of gum problems, prevention of tooth erosion and smoking cessation. For the first three of these topics, 'correct' was defined as including messages delivered in the relevant section of the document An Evidence-based Toolkit for Prevention. ${ }^{13}$ For smoking cessation, the guideline pertaining to pharmacy practice was used as a basis, ${ }^{14}$ with any answer constituting the 
Table 4 The number of respondents reporting each level of confidence for each of the four treated oral health topics for the correct group and the incorrect group (no respondents reported 'very unconfident' for any of the four treated topics)

\begin{tabular}{|c|c|c|c|c|c|c|c|c|}
\hline & \multicolumn{4}{|c|}{ CORRECT ANSWERS } & \multicolumn{4}{|c|}{ INCORRECT ANSWERS } \\
\hline & $\begin{array}{l}\text { Very } \\
\text { Confident }\end{array}$ & $\begin{array}{l}\text { Fairly } \\
\text { Confident }\end{array}$ & Neutral & $\begin{array}{l}\text { Fairly } \\
\text { Unconfident }\end{array}$ & $\begin{array}{l}\text { Very } \\
\text { Confident }\end{array}$ & $\begin{array}{l}\text { Fairly } \\
\text { Confident }\end{array}$ & Neutral & $\begin{array}{l}\text { Fairly } \\
\text { Unconfident }\end{array}$ \\
\hline $\begin{array}{l}\text { Prevention of decay } \\
\text { in children }\end{array}$ & 1 & 9 & 4 & 0 & 2 & 11 & 5 & 0 \\
\hline $\begin{array}{l}\text { Prevention/treatment } \\
\text { of gum problems }\end{array}$ & 2 & 16 & 12 & 1 & 0 & 0 & 1 & 0 \\
\hline Prevention of tooth erosion & 1 & 8 & 4 & 2 & 0 & 9 & 8 & 0 \\
\hline Smoking cessation & 13 & 7 & 8 & 1 & 0 & 1 & 2 & 0 \\
\hline
\end{tabular}

defined 'brief intervention' being considered correct. The full results for this can be seen in Table 4. For each topic, if a respondent's answer included a mixture of correct and neutral (that is, neither beneficial nor harmful) statements, it was still classed as correct, whereas any inclusion of harmful advice led to a designation as incorrect. Data for this analysis were available from 32 of the 35 returned questionnaires, as three respondents did not complete the section relating to confidence.

\section{Prevention of decay in children}

The answers for two questions were combined to provide the data for this topic: those regarding the type of toothpaste recommended for use by a six-year-old child and the age to start toothbrushing. A notable number of respondents were classed as incorrect for this topic $(56 \%, \mathrm{n}=18)$, all but two due to the recommendation of a toothpaste containing less than the guideline fluoride concentration for this age group; the other two incorrect respondents' answers comprised one respondent giving an incorrect age to start brushing and the other giving both an incorrect age and toothpaste. Two respondents in the incorrect group were 'very confident' compared to one respondent in the correct group. The numbers of respondents reporting to be 'fairly confident' were similar between the incorrect and correct group (11 and 9 respectively), as were the numbers of respondents reporting to be 'neutral' (5 and 4 respectively).

\section{Prevention/treatment of gum problems}

Again, the answers for two questions were combined to gather data for this topic: those regarding the type of mouthwash recommended for adults for gingivitis/gum disease and oral hygiene aids/products for gingivitis/gum disease. Encouragingly, on this matter $97 \%(n=31)$ of respondents were correct. The only respondent recorded as being incorrect for this was so because no answer was given for either of these questions, this being classed in this way as the opportunity to offer an answer was not taken. The one incorrect respondent was 'neutral' in confidence.

\section{Prevention of tooth erosion}

Forty-seven percent $(n=15)$ of respondents were classed as correct for this topic. The incorrect answers related to failure to recognise acid as the cause of erosion, attention to oral hygiene measures without specificity for erosion, or lack of an answer. None of the incorrect answers given were incorrect in general terms, but rather would not confer any specific benefit in the context of preventing erosion. In the incorrect group nine respondents were 'fairly confident' and eight respondents were 'neutral'. This compares with eight and four respondents respectively in the correct group. Two respondents scored themselves as 'fairly unconfident' despite provision of correct answers.

\section{Smoking cessation}

Smoking cessation advice scored highly for correctness, with 91\% ( $\mathrm{n}=29)$ of respondents giving responses fulfilling the relevant guidelines. All three 'incorrect' responses related to failure to provide an answer, therefore all of those giving an answer for this question were concordant with current guidelines. For this, in the correct group 13 respondents were 'very confident', seven respondents 'fairly confident' and eight respondents 'neutral'. In the incorrect group one respondent was 'fairly confident' and two respondents 'neutral'.
Overall, it seems that for prevention of decay in children and prevention of tooth erosion there is little difference in confidence between respondents in the correct and incorrect groups; the majority of respondents were 'fairly confident' in both the correct and incorrect groups for these two topics. This may mean that the PCAs in the incorrect group are overconfident in giving advice on these two topics; advice which is in fact incorrect or at least not specific to the matter in hand. For these two topics, around half of the respondents were classed as incorrect. For prevention/treatment of gum problems and smoking cessation, very few answers were incorrect, but it can be seen that in the correct group for these there is a clear shift towards confidence whereas in the incorrect group for these in total three respondents were 'neutral' and one respondent was 'fairly confident'.

\section{DISCUSSION}

The results of this study generally show that patients/customers infrequently approach PCAs in community pharmacies for advice on oral health matters, and that the frequency of advice given by respondents mirrors this, being low, suggesting that opportunistic oral health advice and education is not often being given. This is particularly notable for smokers given the effectiveness of brief interventions. ${ }^{15}$ Based on the questions asked in this study, the level of oral health knowledge seems to be reasonable, although some incorrect answers were given. The majority of answers given were appropriate although some answers were not comprehensive, and surely demonstrate that there is good potential for opportunistic advice even with current levels of training. This should be balanced with the risk of incorrect advice being given, as shown 
by this study to be present. On the topics of prevention of decay in children and prevention of tooth erosion there were a significant number of respondents giving incorrect advice, many of whom claimed confidence in giving advice on these topics. It is important for patient/customer safety for PCAs to only offer advice within their individual competency, and to be aware of the areas in which they lack sufficient knowledge to offer advice. The advice given should correlate with that provided by other health professionals and public health campaigns so as not to lead to confusion or mixed messages. It is clear that focused training would be needed to facilitate wider reliable and comprehensive advice. Many respondents have not received any training in oral health, and some of the others appear to have undertaken either very short or self-education courses. Despite an apparent lack of training for many, the vast majority of respondents expressed some confidence in giving advice on all of the topics examined. The overwhelming majority of respondents feel there is a role for PCAs in OHP and correspondingly are keen to expand that role. Research has shown pharmacists to also be keen to pursue a more active role in OHP. ${ }^{7}$

Logic would suggest that if, for example, a patient/customer was purchasing a toothbrush, it could be an opportune moment to provide wider advice on toothbrushing frequency and duration. However, the data from this study show that patients/customers do not frequently ask for this advice. Other studies suggest that enquiries for acute conditions such as toothache and mouth ulcers are relatively common, ${ }^{8}$ which could provide further opportunities. By virtue of their 'frontof-house' position in the pharmacy, PCAs may be particularly well placed to provide this information. Logical would be a system whereby brief and basic advice could be provided by PCAs, with further advice from the pharmacist when needed, who should always be available to advise on more complex matters and provide guidance for PCAs. These opportunistic interventions could possibly not take much time at all, although published figures do not seem to be available.

More formal and organised strategies are also needed. There is already evidence to demonstrate some effectiveness of community pharmacy health promotion strategies in smoking cessation, ${ }^{5,16,17}$ lipid management, ${ }^{5}$ emergency contraception ${ }^{5}$ and immunisation. ${ }^{5}$ A number of pharmacies provide a room on the premises containing material such as videos and books to view or borrow, and some offer counselling services on subjects such as physical exercise and diet. ${ }^{6}$ Currently, community pharmacies are required to participate in up to six PCT-driven campaigns on public health subjects per year. ${ }^{18}$ Data are lacking as to how many of these have involved messages promoting oral health, although there is considerable potential for incorporation of oral health promotion material into such setups. Formal educational programmes could be undertaken by an organised network of pharmacies, with increased involvement of the community, for example in holding special events. Involvement of dental professionals in these events could be beneficial. Well known events such as National Smile Week are well supported by GP and dental practices nationwide and provide opportunities for integration of effort, with a unified message. Better mutual understanding of services between primary care professions on a local level could aid development of a fine-tuned referral pathway maximising the opportunities for health gain in each individual. There would be many opportunities for PCAs to be involved in all of these activities.

There are some important barriers which may be limiting the extent of involvement of community pharmacies in OHP. Notably, an issue with lack of training provision for PCAs on this subject has been shown by this study. Other studies have noted similar problems for pharmacists. ${ }^{8,19}$ For greater emphasis on OHP to be realistic, the training for both groups would have to be addressed. The availability of time to spend on any of these activities could be a problem, especially in busy pharmacies, and space for displays of educational material may be limited. Input from, and links with, other professionals locally may be also be limited, ${ }^{7}$ which would be important in agreeing an integrated strategy as previously described. Many of the PCAs questioned in this study will work for large or very large pharmacy companies. Many pharmacies may be at the mercy of their company's policy and may be unable to commit resources if these are not forthcoming. Lack of support from the company could therefore act as a barrier, as could the attitude, skills or training of the pharmacists the PCAs work with.

There are some limitations to this study. The response rate, at only 35\%, means the views of only around a third of PCAs are being represented. The reasons for the majority not responding are likely to be diverse but may include a lack of interest in the subject. Postal surveys are a notoriously difficult means by which to obtain responses from a high, and therefore more representative, proportion of the target sample. Therefore at best it can be concluded that a proportion of PCAs are supportive of a role in OHP. As previously mentioned, details of the pharmacy and demographics of the respondent were not collected, therefore disabling this potentially useful line of analysis. It may be that recall bias was introduced by respondents not remembering what training they actually had received, and response bias may result from respondents stating what they think they should do, rather than what they do do. The formatting of the questions as open and the anonymity of the questionnaires were specifically designed to minimise these problems. It may have been difficult for respondents to accurately enumerate retrospectively the number of times advice was requested and provided, especially if the figure decided appeared borderline between two frequency groups. Also, in some cases it may have been difficult for respondents to select the category which most accurately describes how confident they are. Some of the respondents may work part-time, thus possibly affecting the frequency of enquiries and advice opportunities. Despite these shortcomings, we feel this study provides useful data to serve as a preliminary exploration in this area. Further research is needed - the views of patients/customers, and the acceptability and the effectiveness of PCA involvement are issues that are not addressed here. Assurances should be sought in a larger prospective study that PCAs can give correct advice that is resource-realistic and well accepted, before more widespread development in this area can be advocated.

\section{CONCLUSIONS}

This study has shown at least a significant proportion of PCAs to be keen on 
increasing their current role in OHP, and has shown that despite a lack of training some knowledge is there that would be of value to patients/customers. An expanded role should come in a combination of increased opportunistic education, which due to infrequent enquiry ought to be more proactive and diverse, and a more integrated position of pharmacy within a holistic health promotion strategy.

\section{RECOMMENDATIONS}

- Increased opportunities for PCA training in OHP, both as part of startof-career programmes and CPD courses

- Further research, via prospective data collection from a larger sample, to examine the demand and possibilities for opportunistic oral health advice in community pharmacies, and the comprehensiveness and correctness of oral health advice that is or could be provided in community pharmacies

- Further research to explore the logistical and financial practicalities and patient acceptance of any oral health advice provided in community pharmacies
- If the results of these pieces of further research are favourable, a pilot involving a suitably equipped and trained whole-pharmacy team may be reasonable.

1. Anderson S. Public health past and present. Community pharmacy and public health in Great Britain, 1936 to 2006. How a phoenix rose from the ashes. J Epidemiol Community Health 2007; 61: 844-848.

2. Department of Health. Our healthier nation: a con tract for health. London: Department of Health, 1998.

3. Royal Pharmaceutical Society of Great Britain. Council resolves to increase pharmacy's public health role. News release. London: Royal Pharmaceutical Society of Great Britain, 2005.

4. Department of Health. Choosing better oral health: a better oral health plan for England. London: Department of Health, 2005.

5. Pharmaceutical Services Negotiating Committee National Pharmaceutical Association, Roya Pharmaceutical Society of Great Britain, PharmacyHealthLink. Public health: a practical guide for community pharmacists. London: National Pharmaceutical Association, 2004.

6. Anderson C. Health promotion in community pharmacy: the UK situation. Patient Educ Couns 2000; 39: 285-291.

7. Maunder P E V, Landes D P. An evaluation of the role played by community pharmacies in oral healthcare situated in a primary care trust in the north of England. Br Dent J 2005; 199: 219-223.

8. Dickinson C, Howlett J A, Bulman J S. The role of the community pharmacist as a dental health advi sor. Community Dent Health 1995; 12: 235-237.

9. Gilbert $L$. The role of the community pharmacist as on oral health advisor - an exploratory study of community pharmacists in Johannesburg, South Africa. SADJ 1998; 53: 439-443.
10. Sheridan J, Aggleton M, Carson T. Dental health and access to dental treatment: a comparison of drug users and non-drug users attending community pharmacies. Br Dent J 2001; 191: 453-457.

11. Royal Pharmaceutical Society of Great Britain. Training requirements for medicines counter assistants. London: Royal Pharmaceutical Society of Great Britain, 2008

12. Grant $L, B r y s o n ~ S$. The development of health promotion for community pharmacists in Greater Glasgow (1995-99). The Pharmaceutical Journal 2001; 266: 511-513

13. Department of Health. Delivering better oral health - an evidence-based toolkit for prevention. London: Department of Health, 2007.

14. National Institute for Health and Clinical Excellence. Smoking cessation services in primary care, pharmacies, local authorities and workplaces, particularly for manual working groups, pregnant women and hard to reach communities. PH10. London: NICE, 2008. http://www.nice.org.uk/nicemedia/ live/11925/39596/39596.pdf.

15. Dyer T A, Robinson P G. General health promotion in general dental practice - the involvement of the dental team. Part I: a review of the evidence of effectiveness of brief public health interventions. Br Dent J 2006; 200: 679-685.

16. Bauld L, Chesterman J, Ferguson J, Judge K. A comparison of the effectiveness of group-based and pharmacy-led smoking cessation treatment in Glasgow. Addiction 2009; 104: 308-316.

17. Sinclair H K, Bond C M, Stead L F. Community pharmacy personnel interventions for smoking cessation. Cochrane Database Syst Rev 2004; 1: CD003698.

18. Pharmaceutical Services Negotiating Committee. NHS community pharmacy contractual framework essential service - promotion of healthy lifestyles (public health). London: Pharmaceutical Services Negotiating Committee, 2007.

19. Chestnutt I G, Taylor M M, Mallinson E J. The provision of dental and oral health advice by community pharmacists. Br Dent J 1998; 184: 532-534. 